\title{
Detection of Antibodies to Human T-Cell Leukemia Virus Types 1 and 2 in Breast Milk from East Asian Women
}

\author{
Futoshi Matsubara, ${ }^{*, a}$ Yasuko Sagara, ${ }^{b}$ Yoshihisa Kato, ${ }^{c}$ Kouji Harada ${ }^{d}$ Akio Koizumi, ${ }^{d}$ and \\ Koichi Haraguchi ${ }^{e}$ \\ ${ }^{a}$ Department of Microbiology and Biochemistry, Daiichi University of Pharmacy; ${ }^{e}$ Department of Analytical \\ Chemistry, Daiichi University of Pharmacy; 22-1 Tamagawa-cho, Minami-ku, Fukuoka 815-8511, Japan: \\ ${ }^{b}$ Department of Quality, Japanese Red Cross Kyushu Block Blood Center; 1-2-1 Kamikoga, Chikushino, Fukuoka \\ 818-8588, Japan: ${ }^{c}$ Department of Pharmacokinetics and Pharmacodynamics, Kagawa School of Pharmaceutical \\ Sciences, Tokushima Bunri University; 1314-1 Shido, Sanuki, Kagawa 769-2193, Japan: and ${ }^{d}$ Department of \\ Health and Environmental Sciences, Kyoto University Graduate School of Medicine; Yoshida, Sakyo-ku, Kyoto \\ 606-8501, Japan.
}

Received July 16, 2013; accepted October 29, 2013

We investigated the incidence of human T-cell leukemia virus type I (HTLV-1) infection in a total of 17 regions in four countries, including 13 regions in Japan, as well as Korea (Seoul and Busan), China, and Vietnam, by testing breast milk using a particle agglutination assay (PA) and line immunoassay (LIA). Among 266 samples from Japan, 24 (9.0\%) were positive on PA and 3 (1.1\%) were positive on LIA. Among 50 samples from Seoul, 2 were positive on PA and 1 was positive on LIA. In contrast, all 50 samples from Busan were negative on both tests, suggesting the maldistribution of HTLV-1 infectants in South Korea. The numbers of positive samples were 2/91 on PA and 1/91 on LIA for China and 1/88 on both PA and LIA for Vietnam. In China, one sample with a high probability of HTLV-2 infection was identified by LIA and synthetic peptide enzyme-linked immunosorbent assay (ELISA). We examined HTLV-1 antibody in breast milk samples using commercially available test kits, suggesting the existence of HTLV-1 carriers in endemic areas in Southeast Asia and an HTLV-2 infectant in China. As a part of human ethno-epidemiological research, these results constitute valuable epidemiological data. Further studies on the sensitivity, specificity, and reliability of assays using antibodies to HTLV-1 and 2 in breast milk will be necessary for large-scale epidemiological surveys of HTLV infection.

Key words breast milk; human T-cell leukemia virus type II; line immunoassay; particle agglutination assay

Adult T-cell leukemia (ATL) is a malignant CD4-positive T-cell neoplasm caused by infection with human T-cell leukemia virus type I (HTLV-1). Because HTLV-1 is a retrovirus, its genomic RNA is incorporated into target cells, and DNA is incorporated into the host genome as a provirus via reverse transcriptase. ${ }^{1,2)}$

The prevalence of ATL is $0.2-0.3 \%$, and a route of infection that poses a particular issue is vertical transmission (mother-child transmission) via breast milk. ${ }^{2,3}$ ATL is endemic in equatorial Africa, the Caribbean islands, Colombia, Brazil, south India, Papua New Guinea, northeast Australia, and among indigenous people living at the margins of the Andes plateau in South America; in Japan, the infection rate is highest in western Japan, particularly Kyushu. ${ }^{3-5}$ )

In addition to blood transfusions and sexual intercourse, HTLV-1 infection can be transmitted from mother to child via breast milk, with the cause of vertical transmission being infection via lymphocytes in breast milk. ${ }^{1-3)}$ Pregnant women who are carriers must switch to infant formula in order to prevent infection. HTLV-1 testing is required for all pregnant women in Japan, with the main test methods used comprising antigen or antibody testing of blood. ${ }^{4)}$ Recently, ATL provirus DNA testing using automated nucleic acid purifiers has also been investigated. ${ }^{6}$ In developing countries, however, blood testing may not always be adequate.

HTLV-2 has also been isolated from individuals other than leukemia patients, and its association with disease remains

The authors declare no conflict of interest. unclear. Although HTLV-2 carriers have been reported to be common in Central and South America, the regional distribution of HTLV-2 has not been investigated in detail. ${ }^{7)}$

In our preceding paper, ${ }^{8)}$ we reported for the first time that the gelatin particle agglutination (PA) method can be used to measure HTLV-1 antibody in breast milk, which can be sampled non-invasively and is the major source of infection. This PA method is comparatively easy to use as needed, in both the laboratory and the field. For confirmatory testing, HTLV-1 was examined using the Innogenetics ${ }^{\mathrm{TM}}$ Inno-lia $^{\mathrm{TM}}$ HTLV I/II Score. A combination of PA and line immunoassay (LIA) was used on breast milk.

The purpose of this study was to develop a screening assay for the detection of antibodies to HTLV-1/2 in breast milk from East Asian women and to further examine HTLV-1 and HTLV-2 incidence using the Innogenetics ${ }^{\mathrm{TM}}$ Inno-lia $^{\mathrm{TM}} \mathrm{HTLV}$ I/II Score and synthetic peptide enzyme-linked immunosorbent assay (ELISA).

\section{MATERIALS AND METHODS}

Specimens A total of 545 breast milk samples (Beijing, 91; Hanoi, 88; Seoul, 50; Busan, 50; Okinawa, 33; Nagasaki 28, Yamaguchi, 20; Okayama, 20; Kochi, 10; Hyogo, 20; Wakayama, 15; Kyoto, 20; Fukui, 20; Gifu, 20; Tokyo, 20; Miyagi, 20; and Hokkaido, 20) were collected between 2004 and 2010, and were archived in the Kyoto University Human Specimen Bank. Written informed consent was obtained from all participants. The bank project was reviewed ${ }^{9)}$ and approved 
by the Ethics Committee of the Kyoto University Graduate School of Medicine on 14 November 2003 (E25).

PA Screening tests were performed using 545 breast milk samples and a commercially available SERODIA HTLV-1 test kit (Fujirebio Inc., Tokyo, Japan) for in vitro diagnosis. ${ }^{10)}$ The kit includes HTLV-1 antigen-coated gelatin particles that agglutinate in the presence of HTLV-1 antibody in human serum or plasma. Test samples $(25 \mu \mathrm{L})$ and positive control serum were prepared by 2 -fold dilution up to $1: 512$. After an equal volume of sensitized particles was added, reactions were visually interpreted in duplicate. The agglutination patterns were interpreted according to the following criteria for an antibody titer of 1/8: negative $(-)$, particles concentrated in the shape of a button with a smooth round outer margin; inconclusive $( \pm)$, particles concentrated in the shape of a compact ring with a smooth round outer margin; positive $(+)$, peripheral agglutination of the particles in a definite large ring with a rough multiform outer margin; and strongly positive $(++)$, a film of agglutinated particles spread out uniformly on the bottom of the well.

LIA PA-positive breast milk was assayed for the presence of HTLV-1 antibodies using INNO-LIA ${ }^{\mathrm{TM}}$ HTLV I/II Score assays (Innogenetics N.V., Gent, Belgium), which were originally designed for testing serum or plasma. Milk samples $(100 \mu \mathrm{L})$ were incubated in troughs containing LIA strips at $25^{\circ} \mathrm{C}$ overnight for $16 \mathrm{~h}$. This incubation was followed by three washing steps with washing buffer before the addition of an alkaline phosphatase anti-human immunoglobulin conjugate. Samples were then incubated for $30 \mathrm{~min}$ at $25^{\circ} \mathrm{C}$. Three washing steps were again performed, followed by incubation with the chromogen 5-bromo-4-chloro-3-indolyl phosphate/ nitroblue tetrazolium for $30 \mathrm{~min}$ at $25^{\circ} \mathrm{C}$. The results were compared to a positive control.

Synthetic Peptide-ELISA (sp-ELISA) LIA-positive breast milk was assayed by sp-ELISA ${ }^{11)}$ using three synthesized peptides (corresponding to the Gag p19 protein 100 to 130 aa, the Env gp46 protein 175 to 199 aa, and the Env gp46 288 to 317 aa) derived from HTLV-1 genome sequence ATK-1. The peptide corresponding to the region of the Env gp46 protein 175 to 199 aa (gp46-175) allowed the discrimination of HTLV-1/2 antibodies.

\section{RESULTS AND DISCUSSION}

We carried out preliminary screening of HTLV-1 antibody using the PA method with a total of 545 samples: 266 from 13 locations in Japan, and 279 samples from China, Vietnam, and South Korea (Seoul and Busan). Of these, 29 samples showed positive or inconclusive patterns of agglutination. LIA of these 29 samples revealed that three were indeterminate for HTLV-1 infection, four were inconclusive, and two were positive. Of the two positive samples, one from China also indicated positivity for HTLV-2, which is an extremely interesting result. Table 1 shows the overall results for PA and LIA. In the agglutination reaction, 516 of the 545 (94.7\%) breast milk samples were negative. Confirmatory testing was required for 29 samples $(5.3 \%)$, comprising 11 in which particles formed a compact ring with a smooth outer margin $( \pm)$, eight in which

Table 1. Screening Assay for Antibodies to HTLV-1 in Breast Milk Samples Using PA and LIA

\begin{tabular}{|c|c|c|c|c|}
\hline Country & Sampling area & Number of samples & Positive on PA & Positive on LIA \\
\hline \multirow[t]{13}{*}{ Japan } & Okinawa & 33 & 7 & 0 \\
\hline & Nagasaki & 28 & 3 & 0 \\
\hline & Yamaguchi & 20 & 0 & 0 \\
\hline & Okayama & 20 & 0 & 0 \\
\hline & Kochi & 10 & 0 & 0 \\
\hline & Hyogo & 20 & 3 & 0 \\
\hline & Wakayama & 15 & 0 & 0 \\
\hline & Kyoto & 20 & 0 & 0 \\
\hline & Fukui & 20 & 0 & 0 \\
\hline & Gifu & 20 & 0 & 0 \\
\hline & Tokyo & 20 & 0 & 0 \\
\hline & Miyagi & 20 & 3 & 2 \\
\hline & Hokkaido & 20 & 8 & 1 \\
\hline \multicolumn{2}{|l|}{ Japan total } & 266 & 24 & 3 \\
\hline \multirow[t]{3}{*}{ China } & Beijing & 91 & 2 & 1 \\
\hline & & & $\pm^{a)}$ & $-{ }^{a)}$ \\
\hline & & & $\pm^{b)}$ & $\pm^{b)}$ \\
\hline \multirow[t]{4}{*}{ Korea } & Seoul & 50 & 2 & 1 \\
\hline & & & $++^{c)}$ & $+^{c)}$ \\
\hline & & & $\pm^{d)}$ & $-{ }^{d)}$ \\
\hline & Busan & 50 & 0 & 0 \\
\hline \multirow[t]{2}{*}{ Vietnam } & Hanoi & 88 & 1 & 1 \\
\hline & & & $\pm^{e)}$ & $\pm^{e)}$ \\
\hline Total & & 545 & 29 & 6 \\
\hline
\end{tabular}

Japanese data were reported by Matsubara et $a l^{8)}$ Year of collection and age of sample donors were as follows: $a$ ) Sep. 2008, 27; b) Feb. 2009, 26; c) Jan. 2010, 31; $d$ ) Feb. 2010, 31; e) Sep. 2008, 19. 
there was peripheral agglutination of the particles in a clear large ring with a rough multiform outer margin $(+)$, and 10 in which a film of agglutinated particles was spread out uniformly on the bottom of the well $(++)$. Table 1 also shows the donor locations of these 29 breast milk samples: seven from Okinawa, three from Nagasaki, three from Hyogo, three from Miyagi, and eight from Hokkaido were positive. Samples from all other Japanese regions were negative. Five samples (1.8\%) from the other countries required confirmation, with two from Beijing, one from Hanoi, and two from Seoul being positive.

HTLV-1 and HTLV-2 were examined using the Innogenetics $^{\mathrm{TM}}$ Inno-lia ${ }^{\mathrm{TM}}$ HTLV I/II Score using 10-fold quantities of samples according to the manufacturer's standard protocol. As shown in Table 1, two samples were positive and four had a deferred pattern. As shown in Fig. 1, a positive pattern for HTLV-2 was observed in one sample from China, and the sample did not react to gp46-175, suggesting that the donor may be an HTLV-2 carrier. Although it is difficult to distinguish between HTLV-1 and HTLV-2 using the PA method, Berini et al. ${ }^{12)}$ reported that the PA sensitivity of HTLV-2 in the blood of carriers is equal to that of HTLV-1.

The incidence of HTLV-1 infection is high in western Japan, particularly in Kyushu, ${ }^{3-5,13)}$ with some cases also found in Hokkaido, ${ }^{14)}$ and it has also been reported in equatorial Africa, the Caribbean islands, Colombia, Brazil, south India, Papua New Guinea, northeast Australia, and among indigenous people living at the margins of the Andes plateau in South America, which represent endemic areas of the virus. ${ }^{2)}$ As shown Table 1, with the exception of Japan, HTLV-1endemic areas are often in developing countries, where blood testing may not be feasible. The PA method uses a freezedried product that is prepared when required, and determination is made by diluting the sample and visually observing agglutination images; thus, it can easily be used for preliminary screening and is effective for use in developing countries.

It seems that the PA positivity ratio in breast milk is higher than that in the blood, but the results of the LIA method in the present study were equivalent to those obtained with blood samples. Thus, although the PA method using breast milk is useful as a first screen, follow-up testing is necessary.

The sp-ELISA method uses ELISA-coated synthetic peptides corresponding to the immunodominant regions of

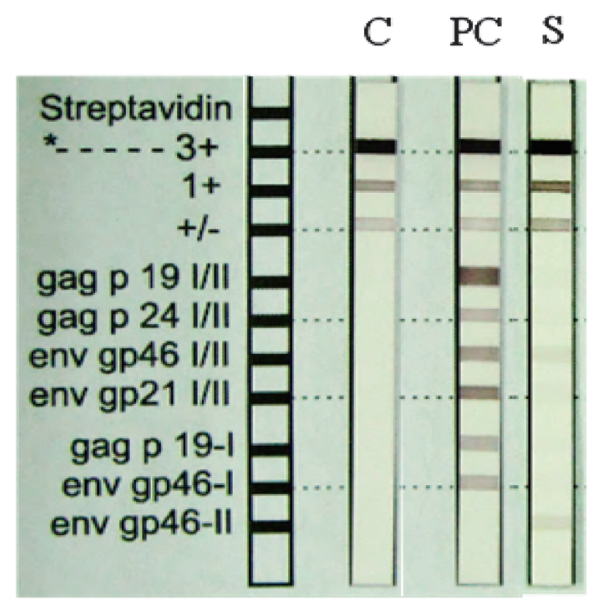

Fig. 1. Positive LIA Reactions of Milk Samples

C, control; PC, positive control; S, milk sample (HTLV-2 ( \pm )).
HTLV-1 structural proteins, ${ }^{11)}$ and for this study we used p19 gag protein (100 to 130 aa), gp46 protein (175 to 199 aa), and gp46 (288 to $317 \mathrm{aa)}$. The peptide corresponding to the region of the Env gp46 protein, 175 to 199 aa (gp46-175), allows the discrimination of HTLV-1/2 antibodies.

HTLV-2 has been isolated from individuals other than leukemia patients, and its association with disease remains unclear. It has also been found in locations including Central and South America, ${ }^{7)}$ Sweden, ${ }^{15}$ Spain, ${ }^{16)}$ and Brazil, ${ }^{17)}$ and its roots are believed to lie in the indigenous peoples of areas such as the Florida peninsula of the United States, the Yucatan peninsula of Mexico, and Panama. ${ }^{5)}$ In this study, it was interesting that we detected an HTLV-2-positive infectant in China.

In countries such as Japan, the United States, France, and the Netherlands, blood donations are routinely checked for a variety of infectious diseases. Recently, China ${ }^{18)}$ and Korea ${ }^{19)}$ have reported epidemiological analyses of HTLV-1 and -2 infection, but in other Asian countries, screening has only been established in the last few years, if at all. ${ }^{20)}$ High-performance antibody screening, such as that on donated blood, is required to assess the status of HTLV infection and to prevent further infection. While it is useful to demonstrate the validity of screening breast milk as opposed to blood, it is important not only to facilitate simpler screening but also highly accurate screening. Further studies on the sensitivity, specificity, and reliability of assays using antibodies to HTLV-1 and -2 in breast milk are necessary for large-scale epidemiological surveys of HTLV infection.

Acknowledgments We thank Ms. Yukiko Inoue for technical assistance with the synthetic peptide-ELISA analyses. This study was supported in part by a Grant-in-Aid for Health Sciences Research from the Ministry of Health, Labour and Welfare of Japan (H21-Food-003), and by Special Coordination Funds for Promoting Science and Technology (No. 1300001) sponsored by the Japan Science and Technology Agency.

\section{REFERENCES}

1) Yamaguchi $K$, Watanabe $T$. Human $T$ lymphotropic virus type-I and adult T-cell leukemia in Japan. Int. J. Hematol., 76 (Suppl. 2), 240-245 (2002).

2) Mylonas I, Brüning A, Kainer F, Friese K. HTLV infection and its implication in gynaecology and obstetrics. Arch. Gynecol. Obstet., 282, 493-501 (2010).

3) Iwanaga $M$, Watanabe $T$, Utsunomiya A, Okayama A, Uchimaru K, Koh KR, Ogata M, Kikuchi H, Sagara Y, Uozumi K, Mochizuki M, Tsukasaki K, Saburi Y, Yamamura M, Tanaka J, Moriuchi Y, Hino S, Kamihira S, Yamaguchi K. Human T-cell leukemia virus type I (HTLV-1) proviral load and disease progression in asymptomatic HTLV-1 carriers: a nationwide prospective study in Japan. Blood, 116, 1211-1219 (2010).

4) Ureta-Vidal A, Angelin-Duclos C, Tortevoye $P$, Murphy E, Lepère JF, Buigues RP, Jolly N, Joubert M, Carles G, Pouliquen JF, de Thé G, Moreau JP, Gessain A. Mother-to-child transmission of human T-cell-leukemia/lymphoma virus type I: implication of high antiviral antibody titer and high proviral load in carrier mothers. Int. J. Cancer, 82, 832-836 (1999).

5) Sonoda S. Present status of HTLV-I infections in developing countries and the countermeasures. Uirusu, 43, 93-100 (1993). 
6) Proietti FA, Carneiro-Proietti ABF, Catalan-Soares BC, Murphy EL. Global epidemiology of HTLV-I infection and associated diseases. Oncogene, 24, 6058-6068 (2005).

7) Higuchi M, Fujii M. Distinct functions of HTLV-1 Tax1 from HTLV-2 Tax2 contribute key roles to viral pathogenesis. Retrovirology, 6, 117 (2009).

8) Matsubara F, Haraguchi K, Harada K, Koizumi A. Screening for antibodies to Human T-cell Leukemia Virus type 1 in Japanese breast milk. Biol. Pharm. Bull., 35, 773-776 (2012).

9) Koizumi A, Harada KH, Inoue K, Hitomi T, Yang HR, Moon CS, Wang P, Hung NN, Watanabe T, Shimbo S, Ikeda M. Past, present, and future of environmental specimen banks. Environ. Health Prev. Med., 14, 307-318 (2009).

10) Fujirebio Inc., Tokyo, Global Sales Department. "Serological test for antibodies to human T lymphotropic retrovirus type I-ParticleAgglutination Test for the Detection of Antibodies to Human T Lymphotropic Retrovirus type I (HTLV-I).”: 〈http://www.fujirebio. co.jp/english/product/serodia.html\#03), cited September, 2012.

11) Washitani Y, Kuroda N, Shiraki H, Itoyama Y, Sato H, Ohshima K, Kiyokawa H, Maeda Y. Linear antigenic regions of the structural proteins of human T-cell lymphotropic virus type I as detected by enzyme-linked immunosorbent assays using synthetic peptides antigens. J. Clin. Microbiol., 30, 287-290 (1992).

12) Berini CA, Susana Pascuccio M, Bautista CT, Gendler SA, Eirin ME, Rodriguez C, Pando MA, Biglione MM. Comparison of four commercial screening assays for the diagnosis of human T-cell lymphotropic virus types 1 and 2. J. Virol. Methods., 147, 322-327 (2008).

13) Zane L, Sibon D, Mortreux F, Wattel E. Clonal expansion of HTLV-1 infected cells depends on the CD4 versus CD8 phenotype.
Front Biosci. (Landmark Ed.), 14, 3935-3941 (2009).

14) Kwon KW, Yano M, Sekiguchi S, Iwanaga M, Fujiwara S, Oikawa O, Sugiura M, Imai S, Osato T. Prevalence of human T-cell leukemia virus type 1 (HTLV-I) in general inhabitants in non-adult T-cell leukemia (ATL)-endemic Hokkaido, Japan. In Vivo, 8, 10111014 (1994)

15) Malm K, Ekermo B, Hillgren K, Britton S, Fredlund H, Andersson S. Prevalence of human T-lymphotropic virus type 1 and 2 infection in Sweden. Scand. J. Infect. Dis., 44, 852-859 (2012).

16) Treviño A, Aguilera A, Caballero E, Benito R, Parra P, Eiros JM, Hernandez A, Calderón E, Rodríguez M, Torres A, García J, Ramos JM, Roc L, Marcaida G, Rodríguez C, Trigo M, Gomez C, de Lejarazu RO, de Mendoza C, Soriano V, HTLV Spanish Study Group. Trends in the prevalence and distribution of HTLV-1 and HTLV-2 infections in Spain. Virology J., 9, 71 (2012).

17) Pinto MT, Rodrigues ES, Malta TM, Azevedo R, Takayanagui OM, Valente VB, Ubiali EM, Covas DT, Kashima S. HTLV-1/2 seroprevalence and coinfection rate in Brazilian first-time blood donors: an 11-year follow-up. Rev. Inst. Med. Trop. São Paulo, 54, 123-129 (2012).

18) Ma Y, Zheng S, Wang N, Duan Y, Sun X, Jin J, Zang W, Li M, Wang Y, Zhao G. Epidemiological analysis of HTLV-1 and HTLV-2 infection among different population in Central China. PLOS ONE www.plosone.org, 8, e66795 (2013).

19) Kwon SY, Lim AH, Park JY, Han SH, Cho NS. Seroprevalence of human T-lymphotropic virus type 1 and 2 Korean blood donnors. J. Med. Virol., 80, 1864-1867 (2008).

20) Abrams A, Akahata Y, Jacobson S. The prevalence and significance of HTLV-I/II seroindeterminate Western blot patterns. Viruses, 3, 1320-1331 (2011). 